\title{
Electrochemical deposition of Ni-TiN nanocomposite coatings and the effect of sodium dodecyl sulphate surfactant on the coating properties
}

\author{
NAFISE PARHIZKAR ${ }^{1}$, ABOLGHASEM DOLATI ${ }^{1}$, ROYA AGHABABAZADEH $^{2}$ and \\ ZAHRA LALEGANI ${ }^{1, *}$ \\ ${ }^{1}$ Department of Materials Science and Engineering, Sharif University of Technology, P.O. Box 11155-9466, Tehran, Iran \\ ${ }^{2}$ Institute for Color Science and Technology, P.O. Box 16765-654, Tehran, Iran
}

MS received 2 July 2015; accepted 21 January 2016

\begin{abstract}
Ni-TiN nanocomposite coatings were prepared by using electrochemical deposition in a Watt's bath containing TiN particles to increase the hardness of $\mathrm{Ni}$. The effects of deposition current density, electrolyte agitation speed and the number of particles in the solution on the amount of incorporated particles in the coating process were investigated. The optimum deposition current density of $4 \mathrm{~A} \mathrm{dm}^{-2}$ and agitation speed of $450 \mathrm{rpm}$ were obtained. The effect of sodium dodecyl sulphate (SDS) anionic surfactant on the amount of particles in the coatings was investigated. It was observed that the maximum amount of incorporated particles, with a value of $7.5 \%$ by volume,

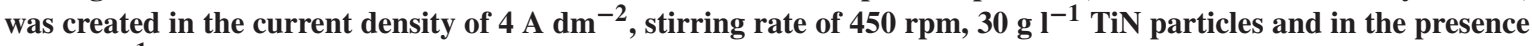
of $0.6 \mathrm{~g} \mathrm{l}^{-1}$ SDS anionic surfactant.
\end{abstract}

Keywords. Electrochemical deposition; nanocomposite; anionic surfactant; sodium dodecyl sulphate.

\section{Introduction}

Many attempts have been made to find methods to improve the surface properties of metal components to protect against wear and corrosion and reducing their costs since all of them are the effective factors in the degradation of industrial parts. Electrodeposition is one of the most important and cost-effective industrial techniques for the production of protective coatings. It is conducted at ambient temperatures and normal pressure and gives high deposition rate and high throwing power. Electrodeposition of $\mathrm{Ni}$ and $\mathrm{Ni}$ alloy coatings has found extensive use in many industrial fields. Compared to Ni coatings, Ni-based composite coatings provide better mechanical properties and higher corrosion and wear resistances [1]. In metal matrix composites, the properties can be modified by the presence of a second phase. The second phase is so hard such as oxides $\left(\mathrm{Al}_{2} \mathrm{O}_{3}, \mathrm{TiO}_{2}, \mathrm{SiO}_{2}\right)$ or carbide particles (SiC, WC), diamond, solid lubricant (PTFE, graphite or $\mathrm{MoS}_{2}$ ), or even liquid-containing microcapsules [2-4].

With the increasing availability of ever decreasing particle sizes, a large number of experts have investigated to a greatest extent the electrocodeposition of micron, submicron and nanoparticles with metallic ions. The main challenge in this area seems to be the deposition of the high levels of non-agglomerated finely dispersed particles. It has been reported that a reduction in particle size would enhance microhardness, ameliorate wear and corrosion resistance [5]. Studies have shown that the properties of composite

*Author for correspondence (zlalegani@yahoo.com) coatings essentially depend on the matrix phases, distribution and the amount of co-deposited particles, which are related to many process parameters, including particle characteristics (particle shape, size and concentration in solution), electrolyte composition (electrolyte concentration, additives, wetting agent, surfactant and concentration) and applied current [6-8]. TiN possesses high hardness, and can be used as secondary phase to enhance strength and toughness of metal or ceramics substrate and hence, TiN nanoparticles would have a good prospect of application as an additive [9].

Because of their high level of surface free energy, nano-TiN particles tend to agglomerate in plating baths. Moreover, high particle concentration and large ionic strength in electrolyte facilitate this agglomeration. These agglomerations make the properties of composite coatings poor. Uniform dispersion of nanoparticles in electrolytes can intensify their participation in coating and improve the coating properties. Several physical and chemical methods have been used for this purpose. Physical techniques, as an example, using destructive energies (e.g., ultrasonic waves) can break the nanoparticles bonds and inhibit the agglomeration; and in chemical techniques, surfactants are used and absorbed on the surface of nanoparticles. Therefore, the repulsion force between particles with the same charges will increase. It reduces the agglomeration and provides a solution with more stable particles [10].

In this study, electrodeposition of $\mathrm{Ni}-\mathrm{TiN}$ nanocomposite was carried out by direct current (d.c.) deposition in a Watt's based bath; and sodium dodecyl sulphate (SDS) compounds was used as a surfactant. The effects of electrodepositing parameters, including TiN particle concentration, cathodic 
Table 1. Basic bath composition and electroplating conditions for $\mathrm{Ni}-\mathrm{TiN}$ composite coatings.

\begin{tabular}{lc}
\hline $\mathrm{NiSO}_{4} \cdot 6 \mathrm{H}_{2} \mathrm{O}$ & $240\left(\mathrm{~g} \mathrm{l}^{-1}\right)$ \\
$\mathrm{NiCl}_{4} \cdot 6 \mathrm{H}_{2} \mathrm{O}$ & $40\left(\mathrm{~g} \mathrm{l}^{-1}\right)$ \\
$\mathrm{H}_{3} \mathrm{BO}_{3}$ & $30\left(\mathrm{~g} \mathrm{l}^{-1}\right)$ \\
Temperature & $50 \pm 2^{\circ} \mathrm{C}$ \\
$\mathrm{pH}$ & $4 \pm 0 / 2$ \\
Current density & $1,2,3,4,6\left(\mathrm{~A} \mathrm{dm}^{-2}\right)$ \\
Stirring rate & $300,450,600,750(\mathrm{rpm})$ \\
TiN particle & $10,20,30\left(\mathrm{~g} \mathrm{l}^{-1}\right)$ \\
SDS $\left(\mathrm{C}_{12} \mathrm{H}_{25} \mathrm{NaO}_{4} \mathrm{~S}\right)$ & $0.05,0.1,0.2,0.3,0.4,0.6,0.8\left(\mathrm{~g} \mathrm{l}^{-1}\right)$ \\
\hline
\end{tabular}

current density and stirring rate, on the coating performance were investigated to optimize the coating properties.

\section{Experimental}

$\mathrm{Ni}$ and Ni-TiN coatings were deposited from a Watt's bath by d.c. electroplating. The basic compositions of bath and the experimental operating parameters are provided in table 1 . All solutions were made with analytical grade chemicals and deionized water. Ni plates with dimensions of $3 \mathrm{~cm} \times 2 \mathrm{~cm} \times$ $0.1 \mathrm{~cm}$ were used as cathode. Prior to electroplating, the $\mathrm{Ni}$ substrates were mechanically polished with $240,600,1000$ and 3000 grit silicon carbide papers, and subsequently rinsed with distilled water and dipped in acetone. All specimens were etched in acid solution (50 vol\% $\mathrm{H}_{2} \mathrm{SO}_{4}+20$ vol\% $\mathrm{HNO}_{3}+15 \mathrm{vol} \% \mathrm{HCl}+10 \mathrm{vol} \% \mathrm{H}_{2} \mathrm{O}$ ) for $10 \mathrm{~s}$ and then rinsed with distilled water. Anode was made of platina.

TiN powder was obtained from Iran Color Research Center and according to the supplier, the average particle size of TiN powder was about $40 \mathrm{~nm}$ [11]. To prevent agglomeration of the TiN particles, electrolytes containing the particles were premixed and stirred by a magnetic stirrer for $12 \mathrm{~h}$ and this suspension was agitated with Watt's bath for $12 \mathrm{~h}$ by a magnetic mixer, and then by ultrasonic agitation for $30 \mathrm{~min}$ just prior to electrodeposition. SDS was added in different concentrations to investigate the performance of surfactant.

Energy-dispersive spectroscopy (EDX) analysis was carried out to define chemical composition of coatings, and the surface of coatings was studied by scanning electron microscopy (SEM). Diamond nanoindenter was used for measuring the hardness of composite coatings and scratch resistance of $\mathrm{Ni}-\mathrm{TiN}$ composite coatings were investigated by atomic force microscopy (AFM).

\section{Results and discussion}

\subsection{Effect of the current density on co-deposition of TiN particles}

To study the effect of current density on TiN content in composite coating, current density is varied from 0.01 to $0.06 \mathrm{~A} \mathrm{~cm}^{-2}$ in solution. TiN content is determined by EDS

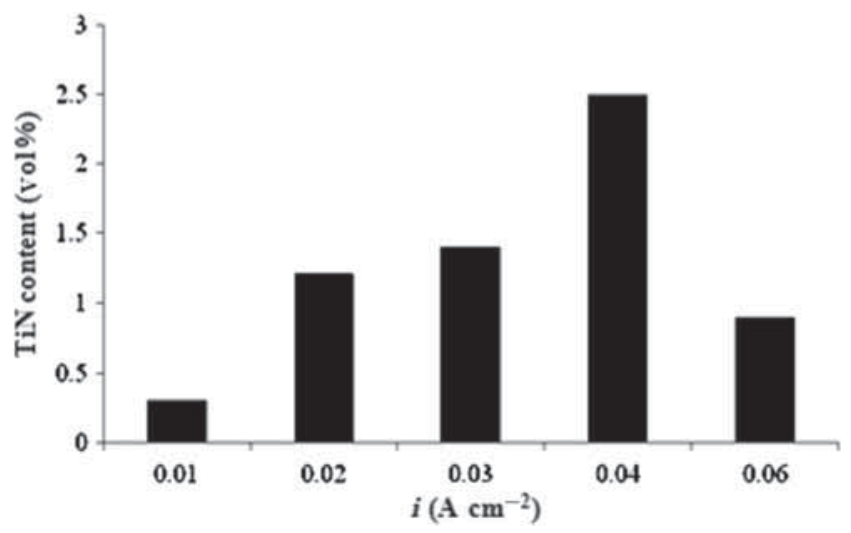

Figure 1. Effect of current density on vol\% incorporation of TiN in the coating at $10 \mathrm{~g}^{-1} \mathrm{TiN}$ and $450 \mathrm{rpm}$.

analysis. The results are demonstrated in figure 1. Maximum amount of $\mathrm{TiN}$ in the coating is $2.5 \mathrm{vol} \%$ and it is achieved in the current density of $0.04 \mathrm{~A} \mathrm{~cm}^{-2}$, as shown in figure 1 . The motion of the ions and particles is controlled by electrical field and agitation of the electrolyte. When the stirring rate is constant, the effect of electrical field stands out [12].

The rate of film growth and volume per cent of incorporated reinforcing particles are determined by the relative magnitudes of the rates at which the particles and cations reached to the growing film surface. Increasing deposition current density can enhance both rates [1]. The value of TiN nanoparticles in the coating is enhanced by increasing the current density up to $0.04 \mathrm{~A} \mathrm{~cm}^{-2}$ and beyond this current density, the TiN nanoparticles content in the coating is decreased. At low densities (less than $0.04 \mathrm{~A} \mathrm{~cm}^{-2}$ ), Ni ions move slowly, leading to a low flux to the cathode. Near the cathode, the Ni ions concentration is low and therefore fewer ions can be adsorbed on TiN particles. Due to this, the Coulomb force between the cathode and anions adsorbed on the particles can be weak, causing a lower vol\% of the co-deposited TiN.

More energy is provided to enhance the convection and diffusion of nanoparticles by increasing the cathodic current density, resulting in the increase of the content of TiN particles in the coating, leading to improvement of the mechanical properties of coating. When the cathodic current density exceeds a certain value $\left(0.04 \mathrm{~A} \mathrm{~cm}^{-2}\right)$, a further increase in the current density would not affect the mobility of the inert particles, but enhances the mobility of ions only [12]; hence, TiN particles concentration on the cathode surface decreases with the electrolytic deposition. As a consequence of this, the content of TiN particles in the coating reduces. In other words, at high current densities, $\mathrm{Ni}$ ions are transported faster than TiN particles that are transported by mechanical agitation and the Coulombic force, which should result in a low vol\% of co-deposited TiN. The occurrence of hydrogen evolution avoids the reduction in the current efficiency and also prevents the adsorption of nanoparticles to the metal surface [13].

Figure 2 shows the mapping images of nanocomposite coating surface of $\mathrm{Ni}-\mathrm{TiN}$ in the optimum current density 

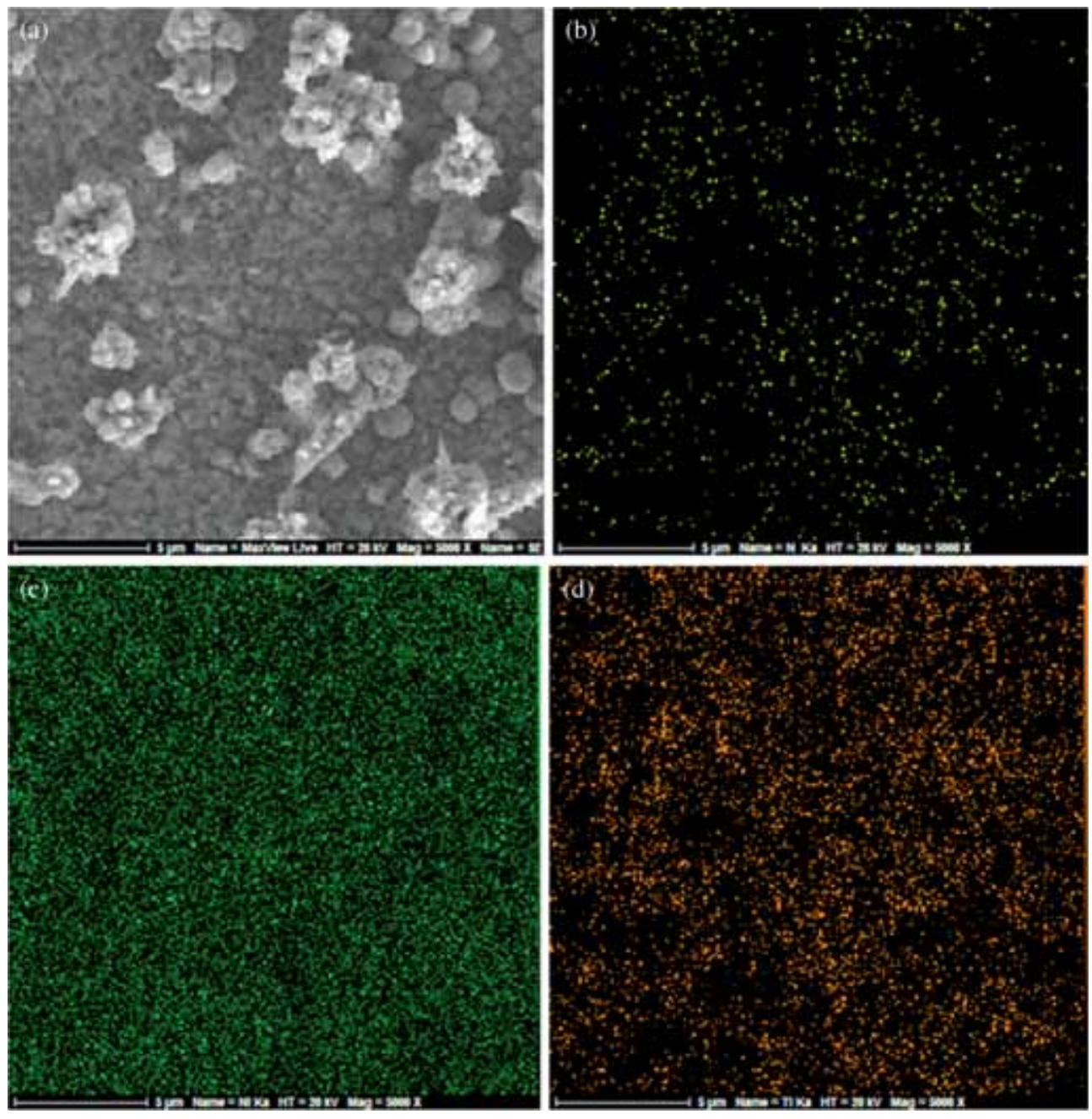

Figure 2. (a) Morphology and mapping image of (b) N, (c) Ni and (d) Ti from nanocomposite coating surface at $0.04 \mathrm{~A} \mathrm{~cm}^{-2}, 10 \mathrm{~g}^{-1} \mathrm{TiN}$ and $450 \mathrm{rpm}$.

and stirring rate. It can clearly be seen that distribution of TiN particles in the Ni matrix is uniform.

\subsection{Effect of stirring rate on co-deposition of TiN particles}

The effect of stirring rate on the vol\% of the co-deposited TiN particulates is shown in figure 3. The stirring rate strongly affects the vol\% of TiN nanoparticles since nanoparticles should be transported to the cathode surface for the codeposition. The vol\% increases with stirring rate and obtains a maximum value at $450 \mathrm{rpm}$, then decreases with the increase in the stirring rate. When the stirring rate is lower than $450 \mathrm{rpm}$, the fluid flow is not capable of transporting all the particulates to the cathode surface and the co-deposition behaviour of TiN particulates is seemingly controlled by particulate transfer. When the stirring rate is too high, the decreasing mode of the weight percentage is mainly caused by the collision factor $[12,14]$. Because of turbulent flow in bath at a high stirring rate, the TiN nanoparticulates on the cathode surface are washed away and so the TiN nanoparticulates percent in composite coating decreases [15]. The

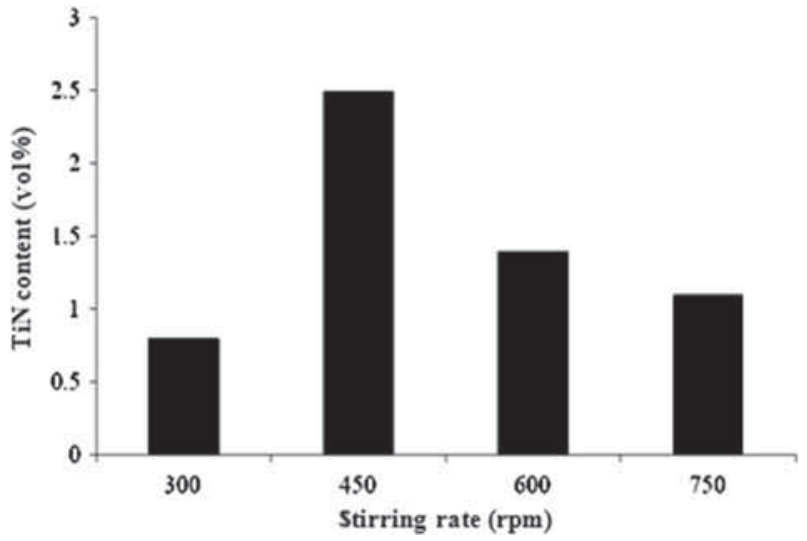

Figure 3. Effect of stirring rate on the vol\% of TiN particulates incorporation in the coating at $10 \mathrm{~g} \mathrm{l}^{-1} \mathrm{TiN}$ and $0.04 \mathrm{~A} \mathrm{~cm}^{-2}$.

obtained results of the current density and electrolyte agitation speed are in agreement with the results reported by Shi et al [14] for $\mathrm{Ni}-\mathrm{Co} / \mathrm{SiC}$ system and by Wang et al [16] for $\mathrm{Cu}(\mathrm{Sn})-\mathrm{Al}_{2} \mathrm{O}_{3}$ system. 


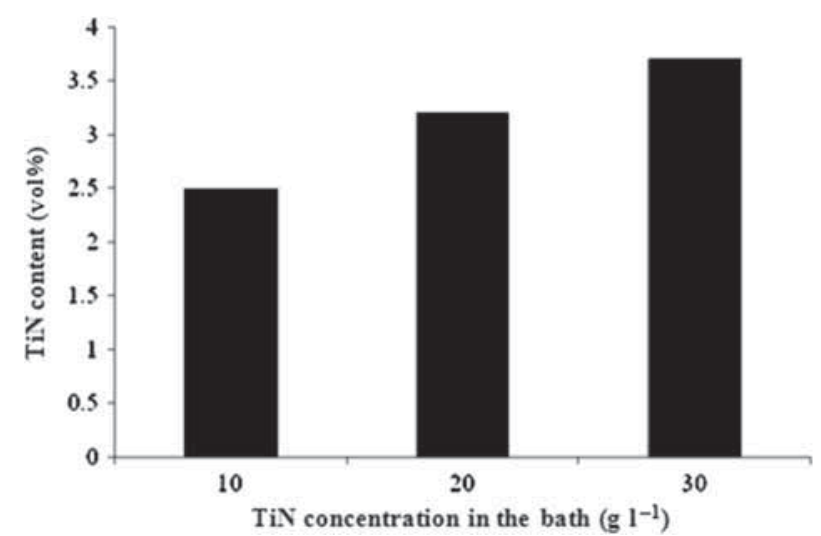

Figure 4. Effect of TiN concentration in the bath on the vol\% of TiN nanoparticulates incorporation in the coating at $450 \mathrm{rpm}$ and $0.04 \mathrm{~A} \mathrm{~cm}^{-2}$.

\subsection{Effect of TiN particle concentration in the bath on co-deposition of TiN particles}

Figure 4 shows the relationship between the vol\% of the co-deposited TiN particulates in the coating and the concentration of the same particulates in the electrolyte. According to figure 4 , the vol\% of the TiN nanoparticulates in the composite coating increases with the increase in TiN particulates content in the electrolyte. The increase in the co-deposited TiN nanoparticulates with increasing TiN particulates content in the electrolyte can be explained by Guglielmi's two-step adsorption model. Therefore, a higher concentration of TiN particulates in the electrolyte enhances the adsorption rate, and resulting in a higher wt $\%$ of the co-deposited $\mathrm{TiN}$ nanoparticulates [14].

\subsection{Effect of SDS surfactant concentration in the bath on co-deposition of TiN particles}

Two common techniques have been used to keep particles suspended in the electrolyte: (1) physical dispersion of particles by bath agitation and (2) chemical dispersion of particles by surfactants [7]. In this research, SDS was used as surfactant and the different concentrations of this surfactant were used. Figure 5 shows the results of EDS analysis as variation of TiN content $v s$. surfactant concentrations. It is observed that the TiN content is increased in the presence of SDS surfactant. SDS is an anionic surfactant and one of its ends is hydrophilic and the other is hydrophobic. When SDS molecules react with the suspended particles in the solution, macroscopic monolayers are formed. The increase of TiN particles in the coating is due to the formation of micelle structure and due to the fact that the hydrocarbonic chain has positive charge and it adsorbs on the surface. When SDS molecules with negative charge are adsorbed on TiN particles, the charge of these particles becomes more negative; therefore the absolute value of zeta potential of particles becomes higher and this increases the repulsive electrostatic force between the particles. On the other hand, these

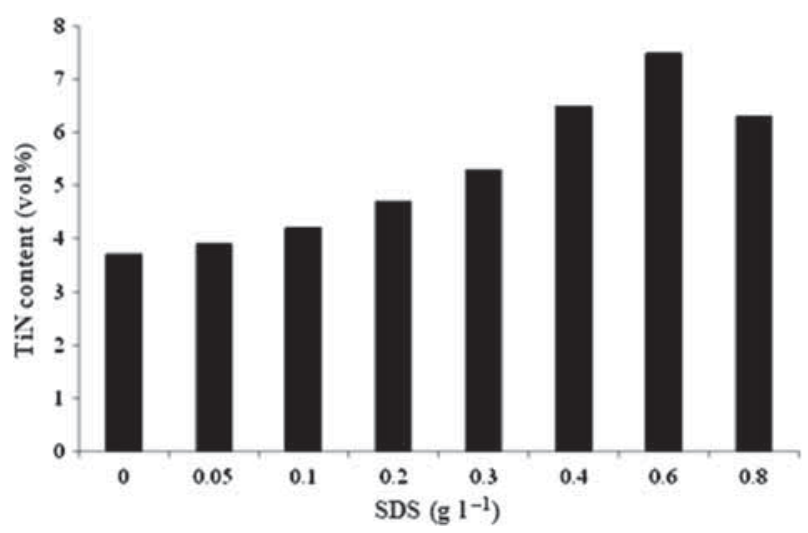

Figure 5. Effect of SDS concentration in the bath on the vol\% of TiN nanoparticulates incorporation in the coating at $30 \mathrm{~g}^{-1} \mathrm{TiN}$, $450 \mathrm{rpm}$ and $0.04 \mathrm{~A} \mathrm{~cm}^{-2}$.

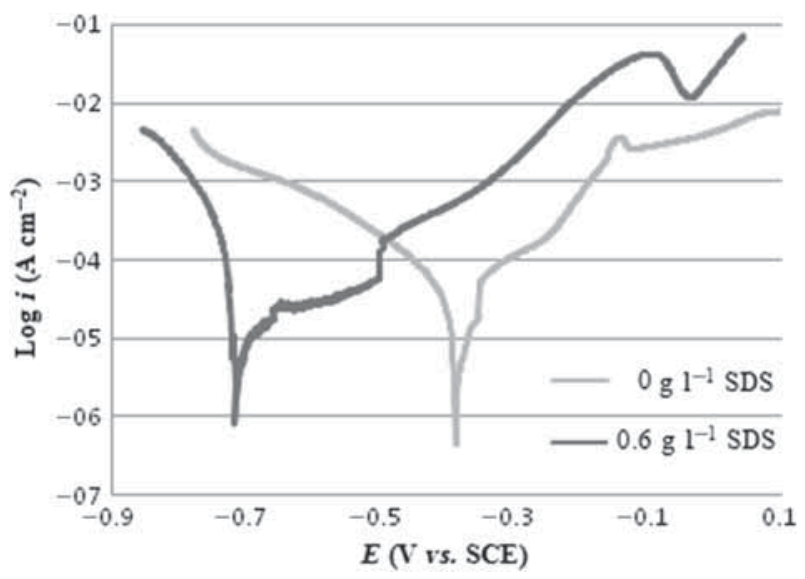

Figure 6. The potentiodynamic polarization curves of $\mathrm{Ni}-\mathrm{TiN}$ composite coatings with SDS and without SDS in $3.5 \mathrm{wt} \% \mathrm{NaCl}$ solution.

Table 2. The results obtained from polarization tests.

\begin{tabular}{lcc}
\hline SDS concentration $\left(\mathrm{g} \mathrm{l}^{-1}\right)$ & $E_{\text {corr }}(\mathrm{mV})$ & $i_{\text {corr }}\left(\mu \mathrm{A} \mathrm{cm}^{-2}\right)$ \\
\hline 0 & -387 & 5 \\
0.6 & -715 & 7.9 \\
\hline
\end{tabular}

particles might be surrounded by $\mathrm{Ni}$ cations and so the second step of Guglielmi's model will not be affected or even it might be enhanced. Hence, the amount of TiN particles in the coating will increase. But if SDS content increases more than optimum $\left(0.6 \mathrm{~g} \mathrm{l}^{-1}\right)$, extra molecules will act as an electrolyte and enhance ionic strength of the bath. This will make the multilayer smaller and decrease electrostatic repulsion and so increases the amount of agglomeration; also, in high amounts of SDS, these molecules may bridge and agglomeration increases. The obtained results are similar to the results reported by Mohajeri et al [2] for Ni-WC system.

Figure 6 shows polarization behaviour of Ni-TiN coatings at $E_{\text {ocp }}$ obtained from electrolytes with SDS and without SDS in $3.5 \mathrm{wt} \% \mathrm{NaCl}$ solution. Table 2 represents the 

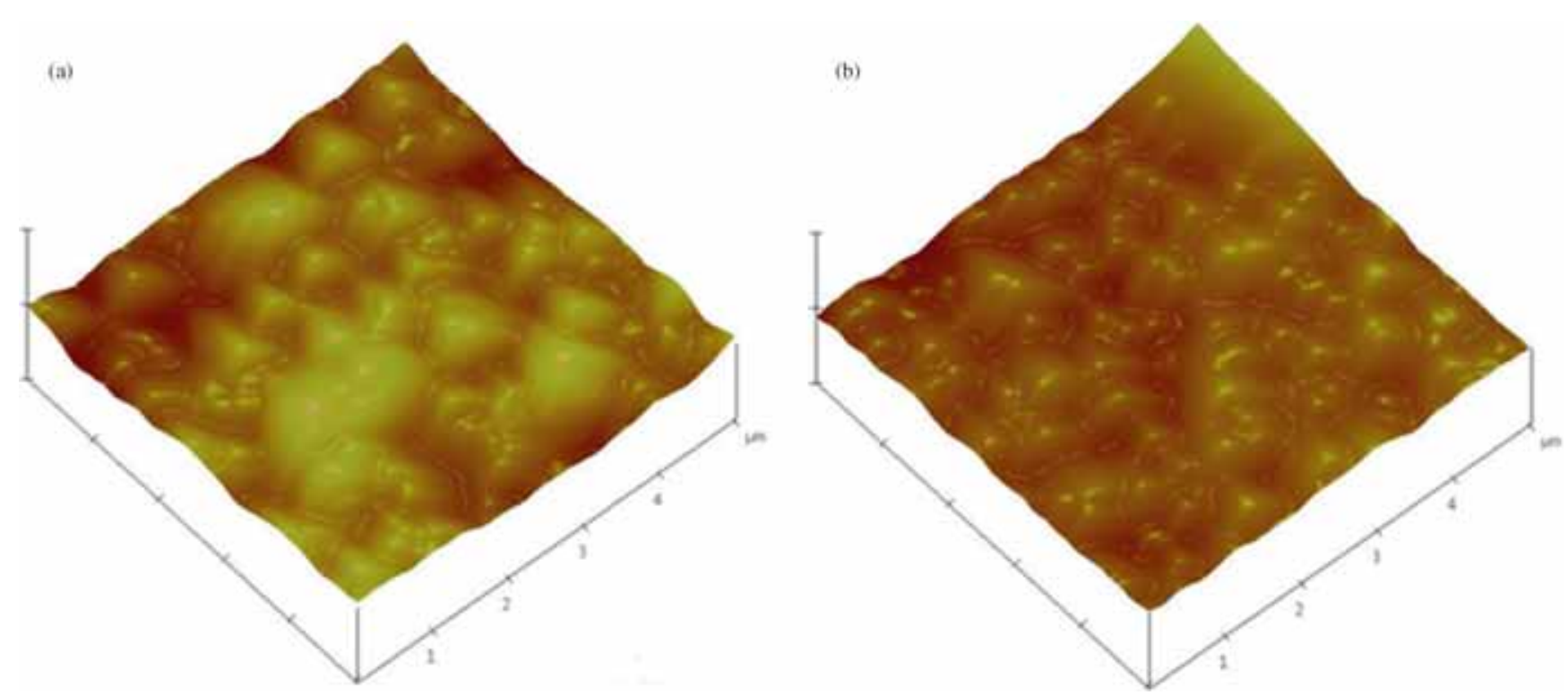

Figure 7. AFM images of (a) pure Ni and (b) optimal nanocomposite coating.

results obtained from polarization tests. The coating obtained from electrolyte without SDS shows better corrosion resistance as compared to electrolyte with SDS. As listed in table 2, the corrosion potential of SDS coatings shows more negative potential when compared to coatings without SDS. The corrosion current density of coating obtained from electrolyte without SDS is lower than the corrosion current density of coating obtained from SDS containing electrolyte. The composites are found to be less corrosion resistant than pure $\mathrm{Ni}$ and while the TiN content increases in the deposit, its corrosion resistance is decreased. In the literature, such behaviours have been reported [17]. The higher corrosion in coating obtained from SDS containing electrolyte can be attributed to higher incorporation of TiN nanoparticles in the coatings, which can lead to an increase in the nuclei number for nucleation of $\mathrm{Ni}$ grains and inhibition of grain growth and so an increase in the density of grain boundaries. It is explained that the initial corrosion starts around the particles, in other words, the metal/particle boundary as the anodic region [17].

One of the effective factors on the corrosion resistance of metallic coatings might be the density of grain boundaries. It was found that corrosion process proceeds along the grain boundaries and aggravates by increasing the grain boundary density. The grain boundaries are more susceptible to corrosion attacks compared to the inter-crystalline parts of the material, because of their higher energy. Therefore, a decrease in grain size leads to a decrease in corrosion resistance. It has been established that the preferential corrosion attacks occur at the interface of the reinforcing particles and matrix because of the formation of microgalvanic cells, which is caused to change the corrosion mechanism from localized corrosion and pitting corrosion to uniform corrosion. The TiN particles act as cathode and the Ni matrix acts as anode in the Ni-TiN composite coatings immersed in the
Table 3. Nanohardness test results of pure Ni electrodeposits and optimal composite coating.

\begin{tabular}{lcc}
\hline Parameters & Ni coating & Ni-TiN coating \\
\hline Hardness (GPa) & 1.86 & 3.23 \\
Elastic modulus (GPa) & 191.8 & 271.5 \\
Max depth $(\mathrm{nm})$ & 253.7 & 194.9 \\
Contact area $\left(\mathrm{nm}^{2}\right)$ & $2.6 \times 106$ & $1.5 \times 106$ \\
\hline
\end{tabular}

corrosive medium, because the standard potential of the TiN particles is more positive than the Ni matrix [1].

\subsection{Nanomechanical properties}

In this study, it was observed that the maximum amount of incorporated particles (with a value of $7.5 \mathrm{vol} \%$ ) is created in the current density of $4 \mathrm{~A} \mathrm{dm}^{-2}$, stirring rate of $450 \mathrm{rpm}$, $30 \mathrm{~g}^{-1}$ TiN particles and in the presence of $0.6 \mathrm{~g} \mathrm{l}^{-1}$ of SDS anionic surfactant. To determine nanomechanical properties, a Berkovich indenter was used to study the nanohardness and nanoscratch resistance of the electrodeposited pure $\mathrm{Ni}$ and optimal composite coatings. Berkovich indenter is a nanoindenter used for testing the hardness of a material [5]. AFM images of pure $\mathrm{Ni}$ coating and optimal Ni-TiN composite coating are shown in figure 7. Table 3 shows the nanohardness test results of pure $\mathrm{Ni}$ electrodeposits and optimal composite coating. The nanohardness value of this composite coating is higher than that of pure Ni plating prepared under the same condition; and also the value of maximum diffusion depth and contact area of pure Ni coating is higher than that of composite coating.

Hardness value of the composite coatings is determined by the properties of the reinforcing particles and matrix 


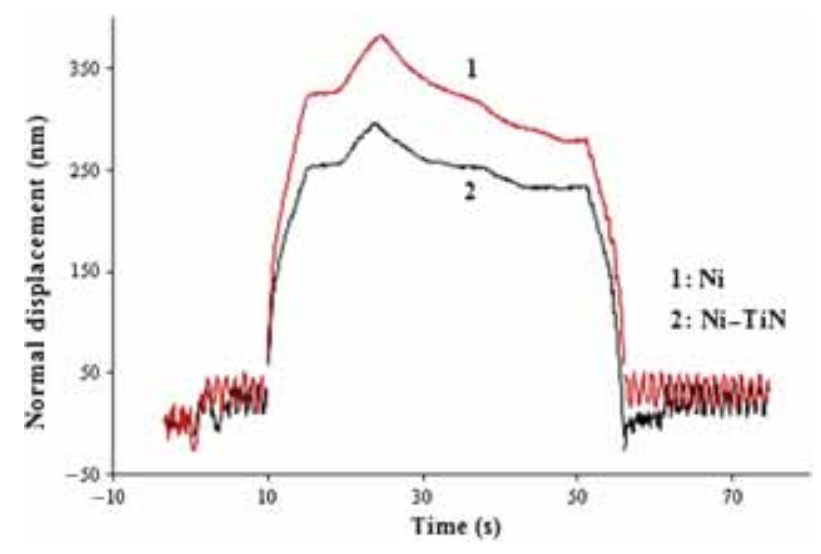

Figure 8. Normal displacement vs. loading time diagrams of the nanoscratch tests for pure $\mathrm{Ni}$ and optimal nanocomposite coating.

material. According to the basic understandings on plastic deformation mechanisms, hardening mechanisms of metal matrix composite coatings are significantly associated with: (1) grain refinement strengthening from the Hall-Petch relationship; (2) dispersion strengthening due to Orowan mechanism [1,18]. The incorporation of reinforcing particles increases the nucleation rate and reduces the grain growth. Reduction of the matrix grain size is an effective way to increase the micro hardness of composite coatings, according to Hall-Petch relation [1]. In case of the dispersion strengthening mechanism, the matrix carries the load and the fine particles impede the motion of dislocations. Strengthening is achieved since the particles restrain the matrix deformation by a nanomechanical constraint [5]. Thus, for the NiTiN nanocomposite in this experiment, the enhancement was related to the dispersion strengthening effect caused by TiN particles that impeded the motion of dislocations in the metallic matrix of the composite coatings and the reduction of the matrix grain size in accordance with the Hall-Petch relation.

Figure 8 shows the normal displacement of the Berkovich indenter into the coatings as the function of loading time. The average depth of scratch in case of the composite coating is less than that of the Ni coating as shown in figure 8 . This behaviour is consistent with the hardness test results and shows the superior scratch resistance of the composite coating in comparison with the pure Ni coating. A competition occurs between the beneficial increase in hardness due to the reinforcing TiN particles codeposited in the $\mathrm{Ni}$ electrodeposits and their adverse lateral effect [5]. Figure 9 shows the lateral force or frictional force as a function of the loading time. The comparison of the lateral force diagrams of the Ni-TiN electrocomposites with those of pure Ni samples, prepared under similar experimental conditions, reveals that TiN embedding causes a decrease of the lateral force. The frictional force has a relationship with the shear strength of the contacting points. The frictional behaviour at the running-in stage of each nanoscratch test is significantly distinct from the one at the steady-state regime because of the change in surface roughness, scratch and accumulation of scratch debris during the test. It means that the initial

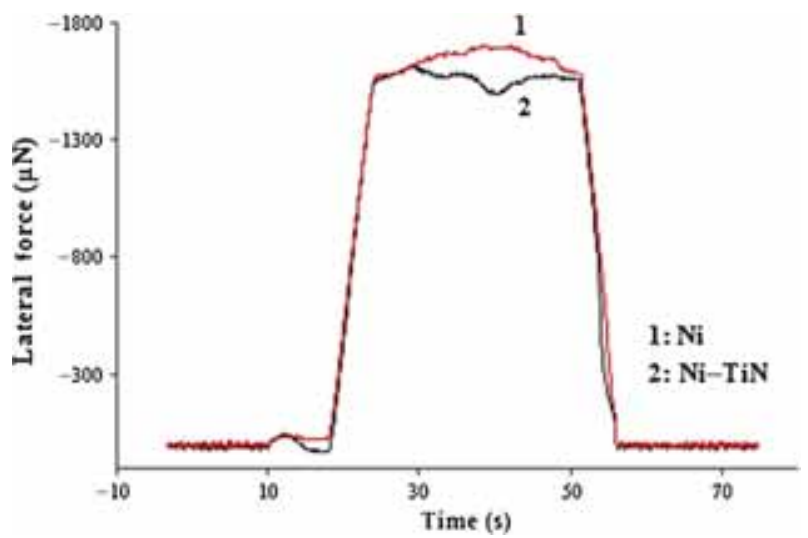

Figure 9. Frictional force as a function of loading time during the scratch test for pure $\mathrm{Ni}$ and optimal nanocomposite coating.

frictional behaviour corresponds to the surface conditions of the counterfaces prior to exposure to the nanoscratch test [13].

\section{Conclusions}

Metal matrix nanocomposites containing ceramic ultrafine particles in a metal matrix are used to improve the mechanical properties such as hardness and wear of coatings. In this work, for increasing hardness and wear resistance of $\mathrm{Ni}$, composite coatings of Ni-TiN was created by using electrochemical deposition of Watt's bath containing TiN particles. In the electrodeposition process, the co-deposition of TiN nanoparticles increased, while current density increased to $0.04 \mathrm{~A} \mathrm{~cm}^{-2}$ value, but decreased as current density passes through the maximum value. In case of electrolyte agitation speed, the co-deposition of TiN nanoparticles increased as stirring rate increases to $450 \mathrm{rpm}$ value, but decreased as stirring rate passes through the maximum value; and in case of TiN content in the bath, the vol\% of TiN in the electrocodeposited layer increases with the increase in TiN content of electrolyte. The effect of incorporation of SDS anionic surfactant was investigated to increase the amount of particles in the coatings. It was observed that the maximum amount of incorporated particles, with a value of $7.5 \%$ by volume, is created in the presence of $0.6 \mathrm{~g}^{-1}$ of SDS anionic surfactant. Corrosion samples were also investigated by using linear polarization in $3.5 \mathrm{wt} \% \mathrm{NaCl}$ solution. It was observed that the increase of incorporated particles in composite coatings, because of the fine grains and increase of boundaries, increases the corrosion current density. The hardness of pure Ni coating and optimal composite coating also was measured and from the results it was observed that the hardness of the coating increased from 1.86 to $3.23 \mathrm{GPa}$ in the presence of particles.

\section{References}

[1] Bakhit B and Akbari A 2012 Surf. Coat. Technol. 2064964

[2] Mohajeri S, Dolati A and Rezagholibeiki S 2011 Mater. Chem. Phys. 129746 
[3] Pompei E, Magagnin L, Lecis N and Cavallotti P L 2009 Electrochim. Acta $\mathbf{5 4} 2571$

[4] Hu F and Chan K C 2005 Appl. Surf. Sci. 243251

[5] Bahadormanesh B, Dolati A and Ahmadi M R 2011 J. Alloys Compd. $\mathbf{5 0 9} 9406$

[6] Xia F, Liu C, Ma C, Chu D and Miao L 2012 Int. J. Refract. Met. H 35295

[7] Low C T J, Wills R G A and Walsh F C 2006 Surf. Coat. Technol. 201371

[8] Afshar A, Ghorbani M and Mazaheri M 2004 Surf. Coat. Technol. 187293

[9] Xu-Bei Z, Chao C, Guo-Qu Z, Zhao Z and Jin-Feng L 2011 T. Nonferrous Met. Soc. 212216

[10] Sabri M, Sarabi A A and Naseri Kondelo S M 2012 Mater. Chem. Phys. 136566
[11] Aghababazadeh R, Mirhabibi A R, Rand B, Banijamali S, Pourasad J and Ghahari M 2007 Surf. Sci. 6012881

[12] Özkan S, Hapçı G, Orhan G and Kazmanlı K 2013 Surf. Coat. Technol. 232734

[13] Sohrabi A, Dolati A, Ghorbani M, Monfared A and Stroeve P 2010 Mater. Chem. Phys. 121497

[14] Shi L, Sun C, Gao P, Zhou F and Liu W 2006 Appl. Surf. Sci. 2523591

[15] Vaezi M R, Sadrnezhaad S K and Nikzad L 2008 Colloids Surf. A 315176

[16] Wang Y L, Wan Y Z, Zhao Sh M, Tao H M and Dong X H 1998 Surf. Coat. Technol. 106162

[17] Marikkannu K R, Amutha K, Paruthimal Kalaignan G and Vasudevan T 2004 International symposium of research students on material science and engineering (Chennai, India) p 1

[18] Abdel Aal A 2008 Mater. Sci. Eng. A 474181 